\title{
AiMT
}

Advances in Military Technology

Vol. 15, No. 2, 2020, pp. 435-451

ISSN 1802-2308, eISSN 2533-4123

DOI 10.3849/aimt.01341

\section{Effect of Target Arrangement and Target Materials Properties on Penetration Depth}

\author{
T. Sy Ngo, S. Beer and P. Konečný* \\ Faculty of Military Technology, University of Defence in Brno, Czech Republic
}

The manuscript was received on 18 July 2019 and was accepted after revision for publication as research paper on 17 November 2020.

\begin{abstract}
:
The article focuses on the development of the new calculation method of jet penetration into the target using ANSYS AUTODYN simulation. The jet formation and its penetration capability dependence on properties of targets are studied. Two kinds of steel armours Armox 440T and S235JR - in standardized plates of thickness $20 \mathrm{~mm}$ are used as materials of the target. The paper contains an analysis of the penetration depth in the targets containing the pure material plates set, combined material plates set and sets of Armox $440 T$ plates with gaps $10 \mathrm{~mm}$ and $20 \mathrm{~mm}$ among individual plates. The theoretical results of simulation are compared with the results of experiments.
\end{abstract}

\section{Keywords:}

ANSYS AUTODYN, Eulerian grid, jet formation, Lagrangian grid, penetration - standoff curve, $P G-7 V$, standoff

\section{Introduction}

Cumulative ammunition with shaped charge is widely used in armies all over the world to destroy numerous types of targets including tanks and other armoured vehicles. A typical modern shaped charge can penetrate steel armour to a depth measured in the diameters of the charge seven or more times.

Due to the relative independence of the jet penetration from impact velocity, the principle of the shaped charge is extensively used for various antitank ammunition or antitank systems, where the warheads have a relatively simple design. On the other hand, the ammunition does not require a weapon barrel loaded by high pressure, which makes the barrel production easier.

It is known that the jet formation and penetration depth in the target also depend on different parameters, such as the shaped-charge hollow angle $\alpha$, the liner material

\footnotetext{
* Corresponding author: Department of Weapons and Ammunition, University of Defence in Brno, Kounicova 156/65, CZ-662 10 Brno, Czech Republic. Phone: +420 973442 037, E-mail: pavel.konecny@unob.cz,ORCID0000-0003-0703-2315.
} 
and thickness, the profile of the wave shaper, the density of the main charge, and the standoff distance [1]. The shaped-charge performance is also affected by the manufacturing technology precision, which includes dimensions tolerance, assembly tolerances, etc. [2]. For reaching the maximum penetration depth in the target, one of the most important factors of the shaped charge is the optimal standoff distance of the warhead.

The research of the armours with various properties and structures, as well as their penetration assessment, is permanently topical with respect to the armoured vehicles ballistic resistance to the penetration.

In this article, the target is created from individual armour $20 \mathrm{~mm}$ plates. The plate thickness was not chosen. They were used according to cost availability. In addition, the manipulation with such plates was very easy due to their mass.

The main objective is an analysis of variable armour material influence and the influence of gaps between the armour material plates on the shaped charge PG-7V penetration effect that was carried out both theoretically by simulation and experimentally.

\section{Materials and Methods}

The jet formation theory is very complex. Many authors have published mathematical models capable to predict the penetration of the armour target by the shaped-charge jet. Penetration theories are given in works [2-12]. All of the models are often simplified, and they do not consider the character of materials too much, especially their dynamics character. In addition, heterogeneity in material properties was not mentioned in previous studies.

The Finite Element Model (FEM) was created using ANSYS AUTODYN [13] software, which is widely used in high explosive detonation simulations, high speed impacts, and other problems areas. The software includes its own material library; however, new materials can be added. The new material addition requires density, equations of state, strength models, and other material properties.

\subsection{Diagram of Solution}

Figs 1-3 show the diagram of solution presented in this article. Based on AUTODYN, the collapse process is built to obtain the velocity and profile of jet, which is shown in Fig. 1. Then, the model was rebuilt using the jet velocity results from the jet formation model to solve the penetration problem in two ways:

- using the gaps between the plates of target,

- using the targets with different materials.

Diagrams of these two cases are shown in Figs 2 and 3, respectively.

\subsection{Materials Properties of PG-7V Warhead Parts}

For simulation problems in this article, it is necessary to determine the characteristics of the main structural elements (parts), including materials of the PG-7V warhead, materials of the target and the materials of the air domain:

- the case of warhead is made of Aluminium,

- the booster charge is from PETN 1.77,

- the explosive A-IX-I is used for main charge,

- the liner is from CuOF-HC, 
- the new material properties have been added for wave shaper.

Two kinds of armour steel were used for the target formation: Armox 440T and S235JR. Compositions and basic properties of Armox 440T were obtained from [14] and S235JR from [15].

Some parts used the material parameters taken from the ANSYS AUTODYN library and the remaining parts used the material parameters obtained from the experiments or from FEM, Inc. Tabs 1-5 introduce the properties of chosen materials.

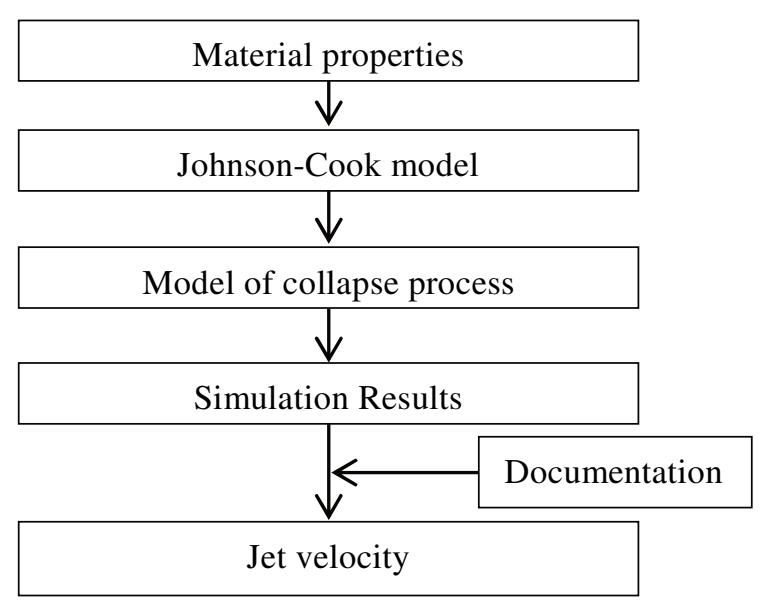

Fig. 1 Diagram of jet formation process

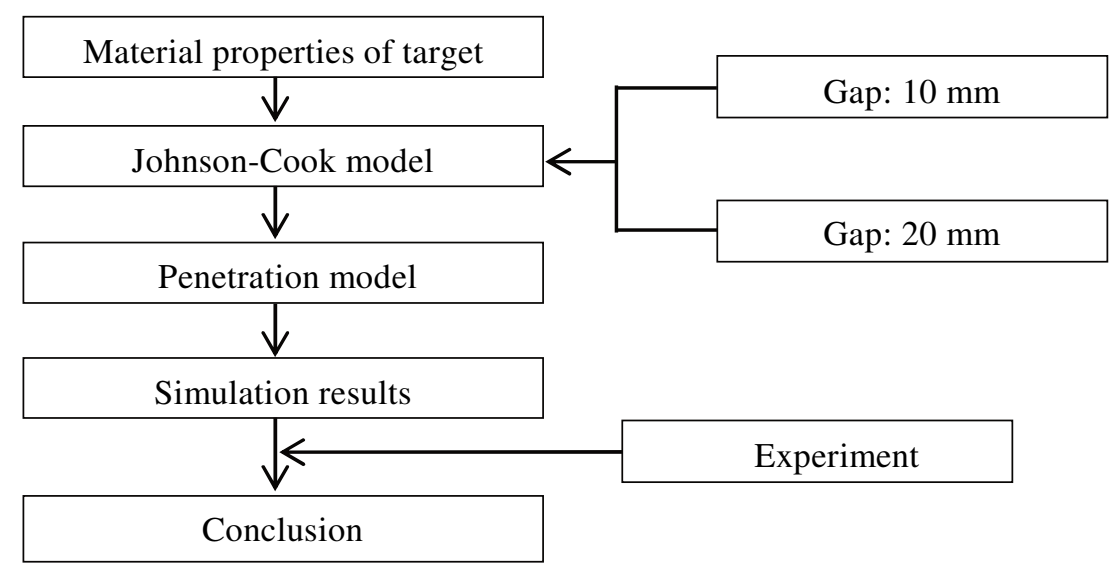

Fig. 2 Diagram of penetration simulation with gaps between plates of target 


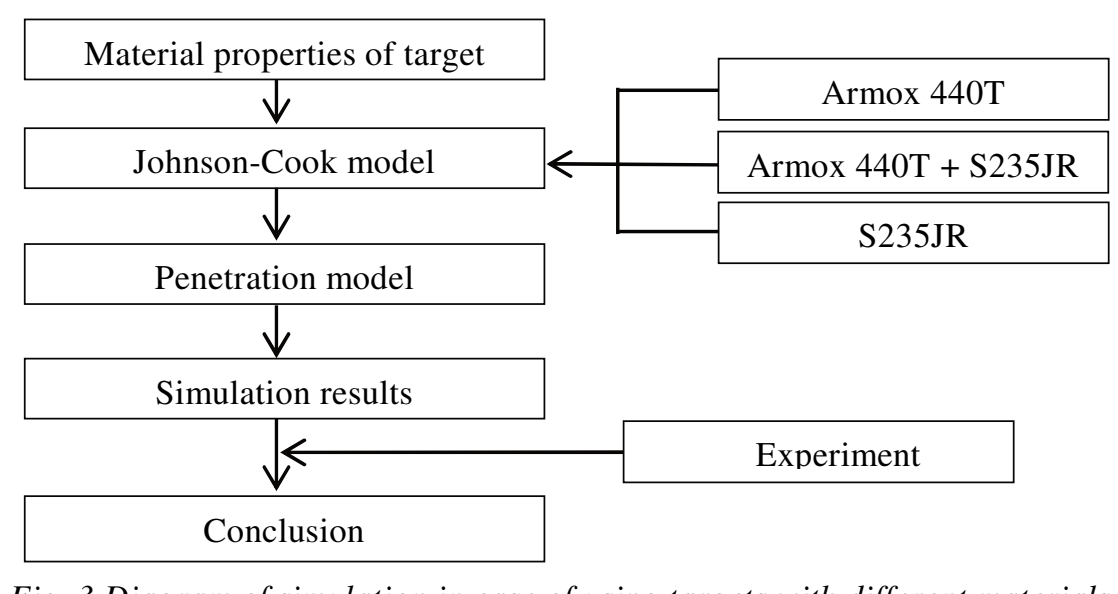

Fig. 3 Diagram of simulation in case of using targets with different materials

Tab. 1 Properties of air

\begin{tabular}{|l|c|c|}
\hline Name & Value & Unit \\
\hline Density & 1.225 & $\mathrm{~kg} \mathrm{~m}^{-3}$ \\
\hline Equation of state & Ideal Gas & - \\
\hline Specific heat ratio & 1.4 & - \\
\hline Temperature & 288 & $\mathrm{~K}$ \\
\hline Specific heat capacity $(v=$ const. $)$ & 0.7175999 & $\mathrm{~kJ} \mathrm{~kg}^{-1} \mathrm{~K}^{-1}$ \\
\hline Initial internal energy & 206.8 & $\mathrm{~kJ} \mathrm{~kg}^{-1}$ \\
\hline
\end{tabular}

Tab. 2 Material properties of booster and main charge

\begin{tabular}{|l|c|c|c|}
\hline Name & Booster & Main charge & Unit \\
\hline Density & 1770 & 1700 & $\mathrm{~kg} \mathrm{~m}^{-3}$ \\
\hline Equation of state & $\mathrm{JWL}$ & $\mathrm{JWL}$ & - \\
\hline Parameter A & $6.17 \times 10^{5}$ & $5.37167 \times 10^{5}$ & $\mathrm{MPa}$ \\
\hline Parameter B & $1.69 \times 10^{4}$ & $5.37926 \times 10^{3}$ & $\mathrm{MPa}$ \\
\hline Parameter R1 & 4.4 & 4.2 & - \\
\hline Parameter R2 & 1.2 & 1 & - \\
\hline Parameter W & 0.25 & 0.4 & - \\
\hline C-J detonation velocity & 8300 & 7500 & $\mathrm{~m} \mathrm{~s}^{-1}$ \\
\hline C-J energy & $1 \times 10^{7}$ & $8 \times 10^{6}$ & $\mathrm{~kJ} \mathrm{~m}^{-3}$ \\
\hline C-J pressure & $3.35 \times 10^{4}$ & $2.9 \times 10^{4}$ & $\mathrm{MPa}$ \\
\hline
\end{tabular}

Tab. 3 Material properties of case, liner and steel S235JR

\begin{tabular}{|l|c|c|c|c|}
\hline Name & Case & Liner & S235JR & Unit \\
\hline Density & 2770 & 8930 & 7896 & $\mathrm{~kg} \mathrm{~m}^{-3}$ \\
\hline Equation of state & Shock & Shock & Shock & - \\
\hline Gruneisen coefficient & 2 & 1.99 & 2.17 & - \\
\hline Parameter C1 & $5.3 \times 10^{3}$ & 3.94 & $4.57 \times 10^{3}$ & $\mathrm{~m} \mathrm{~s}^{-1}$ \\
\hline \multicolumn{5}{|c|}{ Continued on the next page } \\
\hline
\end{tabular}




\begin{tabular}{|l|c|c|c|c|}
\hline Name & Case & Liner & S235JR & Unit \\
\hline Parameter S1 & 1.33 & 1.489 & 1.49 & - \\
\hline Strength model & $\begin{array}{c}\text { Johnson- } \\
\text { Cook }\end{array}$ & $\begin{array}{c}\text { Johnson- } \\
\text { Cook }\end{array}$ & $\begin{array}{c}\text { Johnson- } \\
\text { Cook }\end{array}$ & - \\
\hline Shear modulus & $2.76 \times 10^{4}$ & $4.7 \times 10^{4}$ & $8.18 \times 10^{4}$ & $\mathrm{MPa}$ \\
\hline Yield strength & 337 & 89.7 & 350 & $\mathrm{MPa}$ \\
\hline Hardening constant & 343 & 292 & 275 & $\mathrm{MPa}$ \\
\hline Hardening exponent & 0.41 & 0.31 & 0.36 & - \\
\hline Strain rate constant & 0.01 & 0.025 & 0.022 & - \\
\hline
\end{tabular}

Tab. 4 Material properties of wave shaper

\begin{tabular}{|l|c|c|}
\hline Name & Value & Unit \\
\hline Density & 1385 & $\mathrm{~kg} \mathrm{~m}^{-3}$ \\
\hline Equation of state & Shock & - \\
\hline Gruneisen coefficient & 1.3 & - \\
\hline Parameter C1 & $2.09 \times 10^{3}$ & $\mathrm{~m} \mathrm{~s}^{-1}$ \\
\hline Parameter S1 & 1.35 & - \\
\hline
\end{tabular}

Tab. 5 Material properties of Armox 440T

\begin{tabular}{|l|c|c|}
\hline Name & Value & Unit \\
\hline Density & 7830 & $\mathrm{~kg} \mathrm{~m}^{-3}$ \\
\hline Equation of state & Linear & - \\
\hline Bulk modulus & $1.59 \times 10^{5}$ & $\mathrm{MPa}$ \\
\hline Reference temperature & 300 & $\mathrm{~K}$ \\
\hline Specific heat & 0.477 & $\mathrm{~kJ} \mathrm{~kg}^{-1} \mathrm{~K}^{-1}$ \\
\hline Strength model & Johnson-Cook & - \\
\hline Shear modulus & $7.7 \times 10^{4}$ & $\mathrm{MPa}$ \\
\hline Yield strength & $1.11 \times 10^{3}$ & $\mathrm{MPa}$ \\
\hline Hardening constant & $2 \times 10^{3}$ & $\mathrm{MPa}$ \\
\hline Hardening exponent & 0.85 & - \\
\hline Strain rate constant & 0.002 & - \\
\hline Thermal softening exponent & 1.4 & - \\
\hline Failure model & Johnson-Cook & \\
\hline Damage constant, D1 & 0.051 & - \\
\hline Damage constant, D2 & 0.82 & - \\
\hline Damage constant, D3 & -0.46 & - \\
\hline Damage constant, D4 & -0.04 & - \\
\hline Melting temperature & 1793 & $\mathrm{~K}$ \\
\hline
\end{tabular}

\subsection{Experiment Setup}

The experiments were carried out by the Military Research Institute in Brno at the Bzenec shooting range. The number of PG-7V warheads had been limited, therefore the experiments were carried out according to Tab. 6 . The warhead was placed in an optimal standoff distance from the target $180 \mathrm{~mm}$. The target was built from 17 pieces of Armox 440 plates $(20 \times 200 \times 200) \mathrm{mm}$, which is shown in Fig. 4 . 
Fig. 5 shows the experimental setup when using target with air spaces between Armox 440T plates. The warhead is placed in an optimal standoff from the target. In these tests, the distances of gaps were $10 \mathrm{~mm}$, resp. $20 \mathrm{~mm}$. Fig. 6 shows the experimental setup when using S235JR target. The target is built from 24 pieces of S235JR plates $(20 \times 200 \times 200) \mathrm{mm}$.

Tab. 6 Overview of planned experiments for optimal standoff distance $180 \mathrm{~mm}$

\begin{tabular}{|l|l|c|}
\hline \multicolumn{2}{|l|}{ Experiment } & $\mathbf{N}^{\mathbf{0}}$ of tests \\
\hline Armour material effect & Armox 440 T & 3 \\
without gaps & S235JR & 2 \\
& Armox 440T + S235JR & 1 \\
\hline Gaps Effect & $10 \mathrm{~mm}$ & 2 \\
(Armox 440T): & $20 \mathrm{~mm}$ & 2 \\
\hline
\end{tabular}

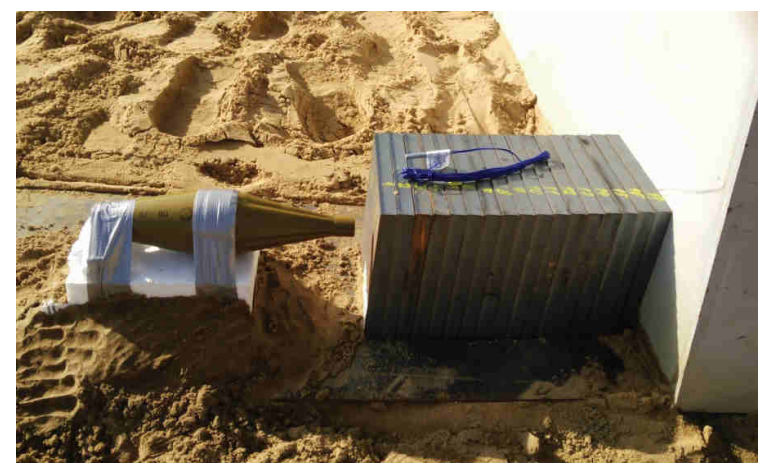

Fig. 4 The test of Armox 440 T target

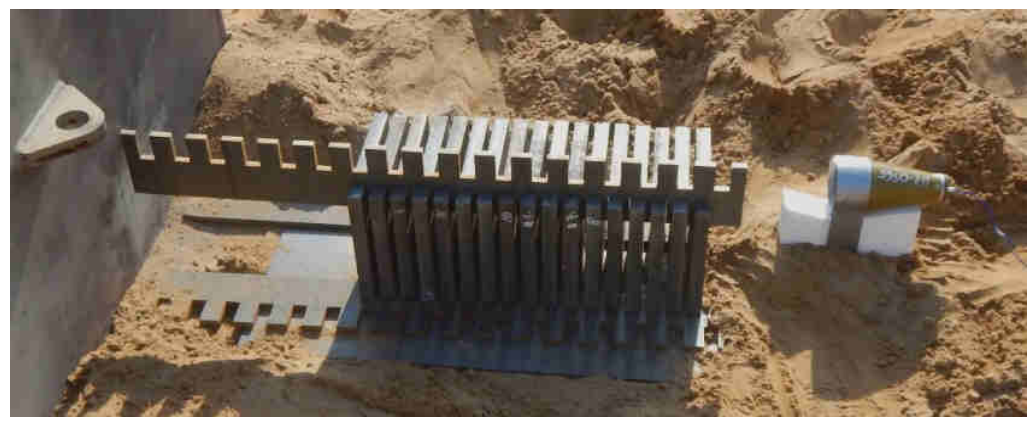

Fig. 5 The target with air space between plates

\section{Simulation of Target Characteristics Effect on Penetration Depth}

The process of the jet formation simulated in the FEM model described the Eulerian grid created a high-speed jet. Then the jet was transferred to the Lagrangian grid with the same coordinate system as in case of the Eulerian grid and the target made of steel armour plates from the Armox 440T was built using the ALE grid. The types of grids used were consulted with the experts from ANSYS company. The materials properties of the jet and target are introduced in Tab. 4 and Tab. 5. 


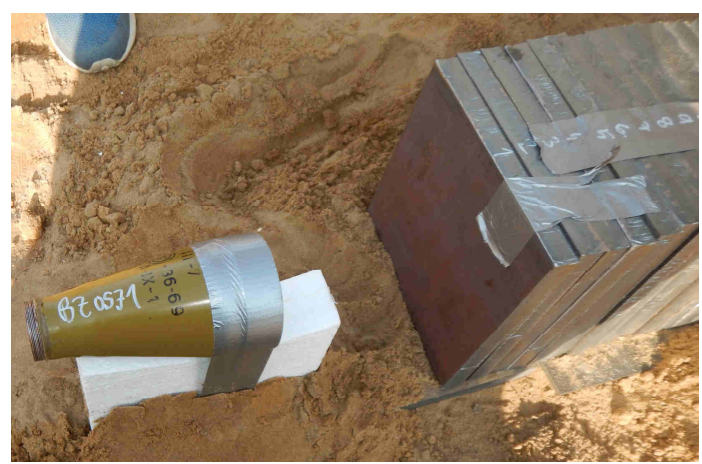

Fig. 6 The test of S235JR target

\section{Simulation of Target Characteristics Effect on Penetration Depth}

The process of the jet formation simulated in the FEM model described the Eulerian grid created a high-speed jet. Then the jet was transferred to the Lagrangian grid with the same coordinate system as in case of the Eulerian grid and the target made of steel armour plates from the Armox 440T was built using the ALE grid. The types of grids used were consulted with the experts from ANSYS company. The materials properties of the jet and target are introduced in Tab. 4 and Tab. 5 .

\subsection{Simulation Model of Jet Formation}

Fig. 7 introduces the PG-7V model used for the jet formation simulation, which includes following parts: booster, case, wave shaper, main charge and liner.

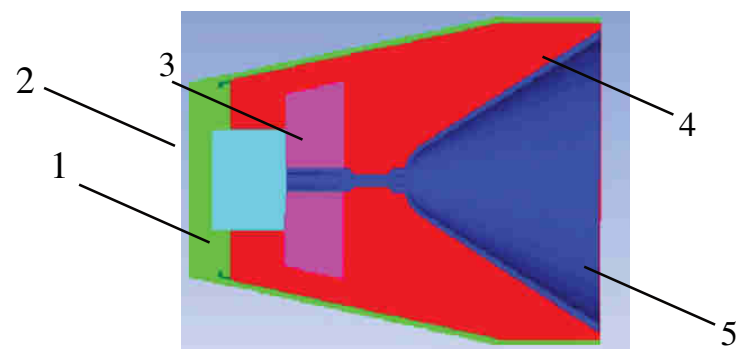

Fig. 7 Model of PG-7V warhead

1. booster; 2. case; 3. waveshaper; 4. main charge; 5. liner

In this model, the front part of the warhead was removed. All dimensions of the model were drawn according to the technical documentation of PG-7V warhead accessible on the Department of Weapons and Ammunition of University of Defence in Brno.

Using ANSYS AUTODYNE software, the FEM model was built up to determine the jet velocity, jet formation as well as the collapse process of the liner. All parts of the jet formation process model were described by an Eulerian grid. The model consists of 2 parts: PG-7V warhead and an air domain in front of it.

A coordinate system was built to determine positions of jet tip at any moment of jet moving. In this coordinate system, the $0 x$ axis is axis of symmetry of the warhead, the rear edge of booster is chosen as $0 y$ axis, and the origin is the intersection point of $0 x$ and $0 y$ axis. The coordinate system of the model was constructed as shown in 
Fig. 8. Series of Gauss points were set on the $0 x$ axis and the liner to obtain the jet tip velocity and other parameters. The detonation line was set at the rear edge of the booster. All parts were filled with materials presented in Tabs 1-4.

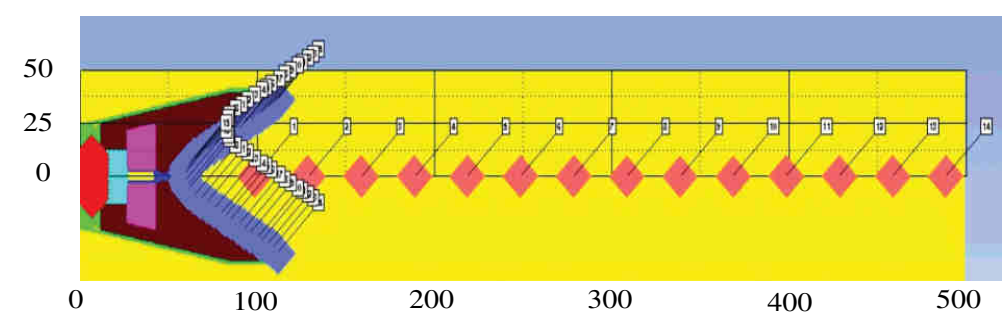

Fig. 8 FEM model of jet formation process

\subsection{Jet Formation Simulation Results}

All cases of simulation as well as experiments were performed when the warheads were located at the optimal standoff distance. According to technical documentation, the distance of the PG-7V warhead from the target to the rear edge of booster was between $318 \mathrm{~mm}$ and $332 \mathrm{~mm}$, depending on the production precision of the warhead.

Based on the simulation results, Fig. 9 shows the graph of the velocity and the profile of the jet in the optimal stand-off distance position. At this moment, the coordinates of the jet tip are $(327 ; 0)$.
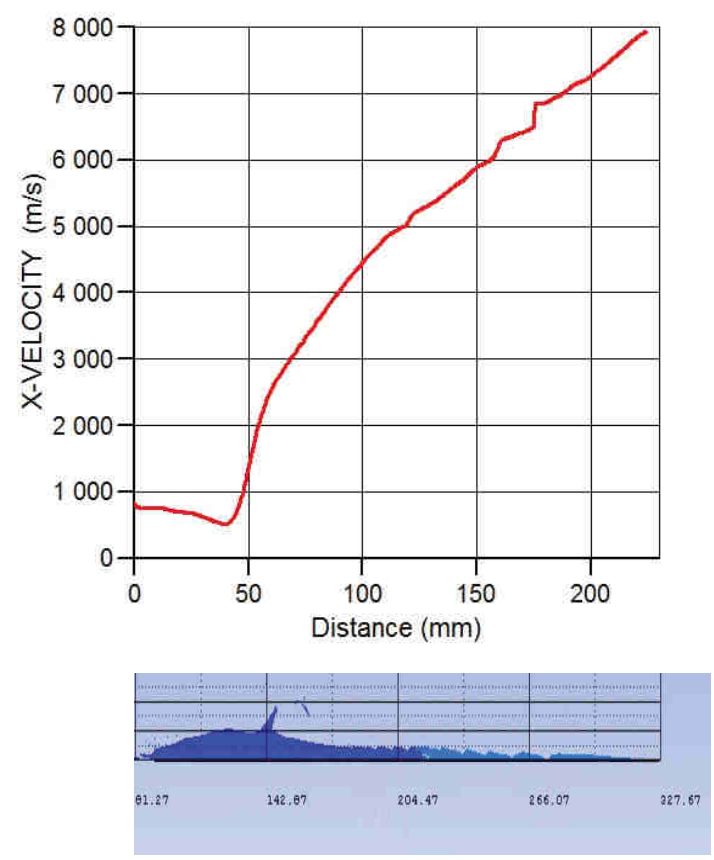

Fig. 9 Jet profile and jet velocity at optimal standoff distance 


\subsection{Influence of Gaps between Target Plates}

Fig. 10 shows the formed jet of the modified PG-7V warhead and the target model with gaps $10 \mathrm{~mm}$ between the plates of the target. In the same way, Fig. 11 shows the jet - target models assembled in the case where gaps are $20 \mathrm{~mm}$.

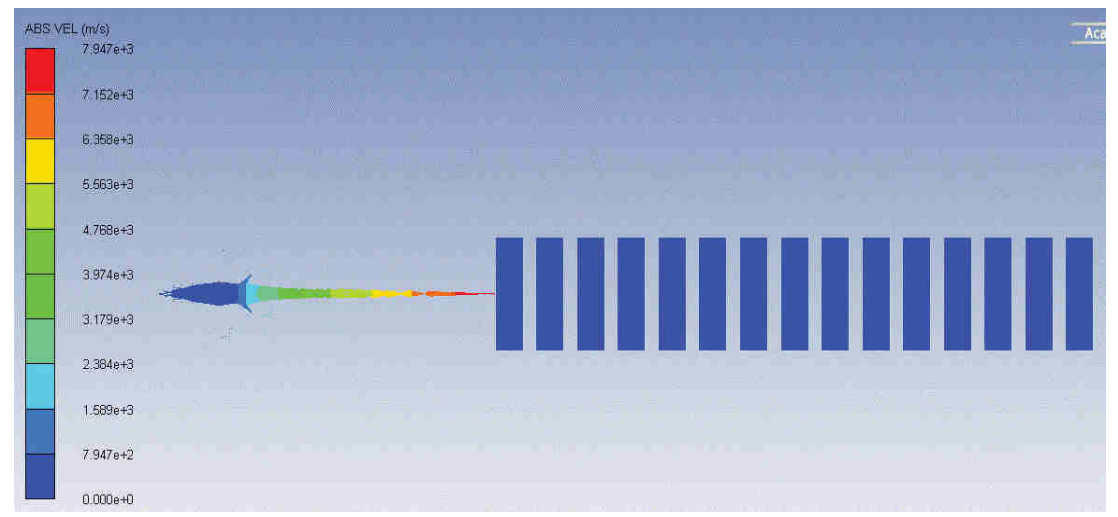

Fig. 10 Penetration model in case of $10 \mathrm{~mm}$ gaps of target

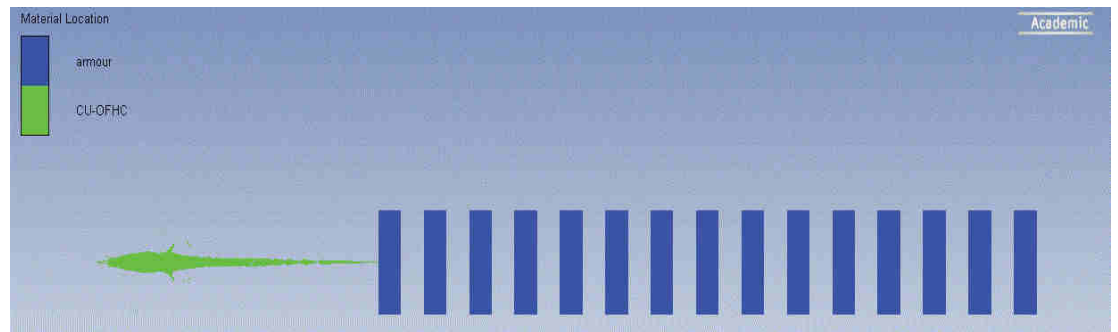

Fig. 11 Penetration model in case of $20 \mathrm{~mm}$ gaps of target

\subsection{Effect of Target Materials Properties on Penetration Depth}

The model of penetration jet into the target made of Armox 440T is shown in Fig. 12. Series of Gauss points were set on the $0 x$ axis to obtain the jet tip velocity and the state of the target at any moment of simulation time.

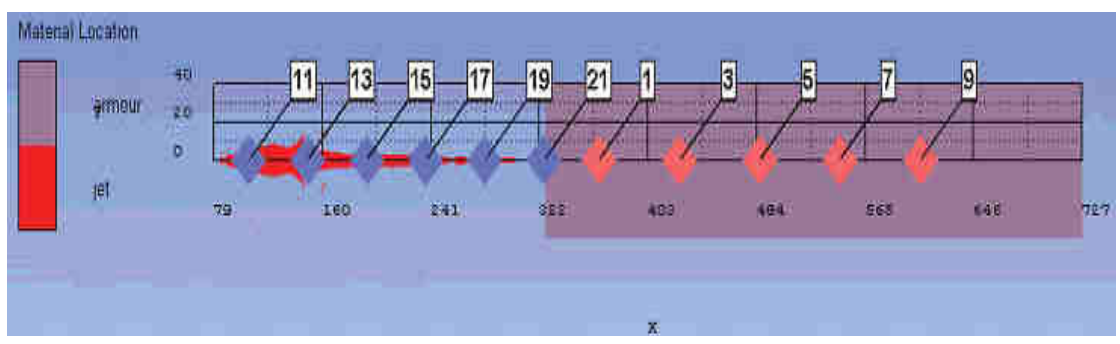

Fig. 12 Penetration model in case of Armox 440T target

In the same way, Fig. 13 shows the formed jet and target model at the optimal standoff distance at the moment of impact on the mixed target, which is formed alter- 
nately of $20 \mathrm{~mm}$ Armox 440T armour plates and $20 \mathrm{~mm} \mathrm{S235JR} \mathrm{plates.} \mathrm{Material} \mathrm{prop-}$ erties of Armox 440T were determined experimentally.

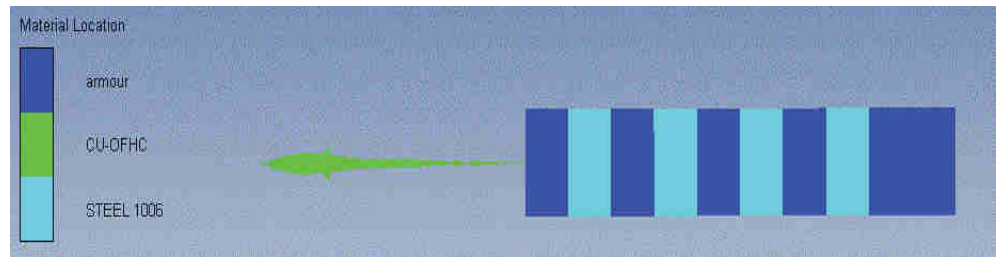

Fig. 13 Penetration model in case of mixed target

Fig. 14 shows the model of penetration of the target formed by the material S235JR.

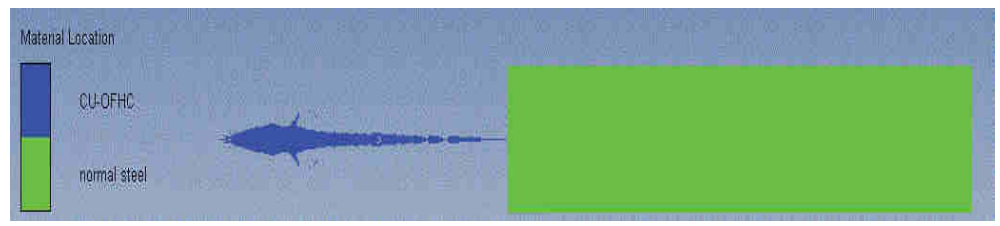

Fig. 14 Penetration model of the target from S235JR

\section{Results and Discussion of Simulation and Experiments}

\subsection{Simulation of Air Spaces Effect between Plates of Target}

The results indicate the state of the jet during the penetration process depending on time. Figs 15 and 16 show the state of jet - target system. The velocity of the jet depends on its length at $9.248 \times 10^{-2} \mathrm{~ms}$ of simulation time. In this case, the gaps size is $10 \mathrm{~mm}$.

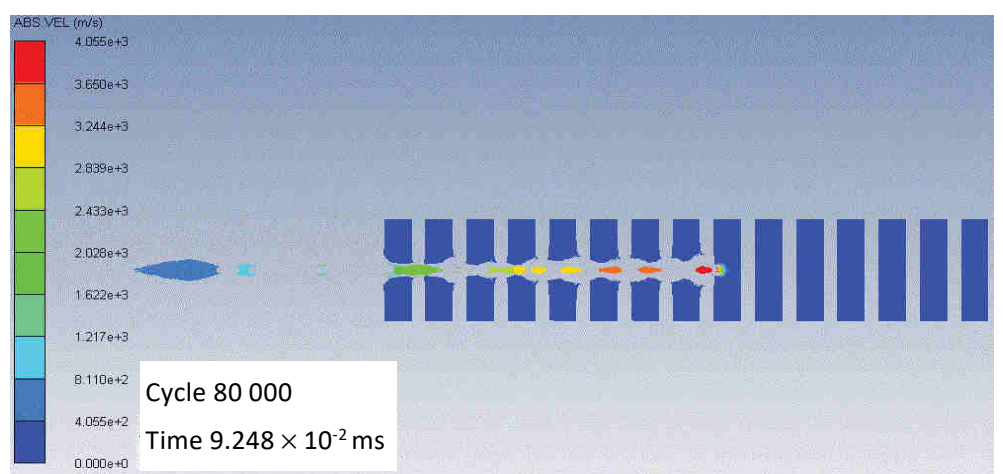

Fig. 15 Jet - target state of $9.248 \times 10^{-2} \mathrm{~ms}$ simulation time

The dependence of the penetration depth on the selected gaps between the plates of the target is shown in Fig. 17. In case of the $20 \mathrm{~mm}$ or greater gaps, the penetration depths do not change significantly. According to the trend of the graph, when the gaps between the plates further increase, the penetration depth will be less affected. 


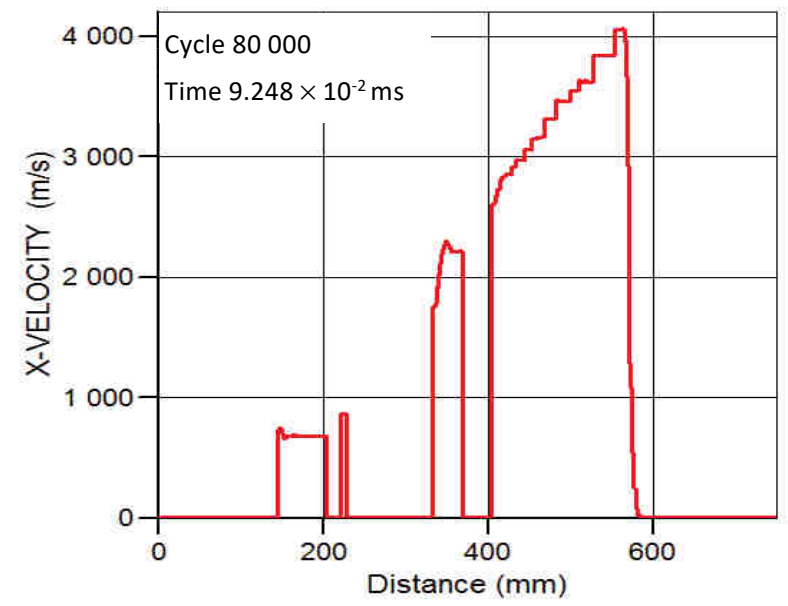

Fig. 16 Velocity of jet depending on its length at the time $9.248 \times 10^{-2} \mathrm{~ms}$

The dependence of the penetration depth on the selected gaps between the plates of the target is shown in Fig. 17. In case of the $20 \mathrm{~mm}$ or greater gaps, the penetration depths do not change significantly. According to the trend of the graph, when the gaps between the plates further increase, the penetration depth will be less affected.

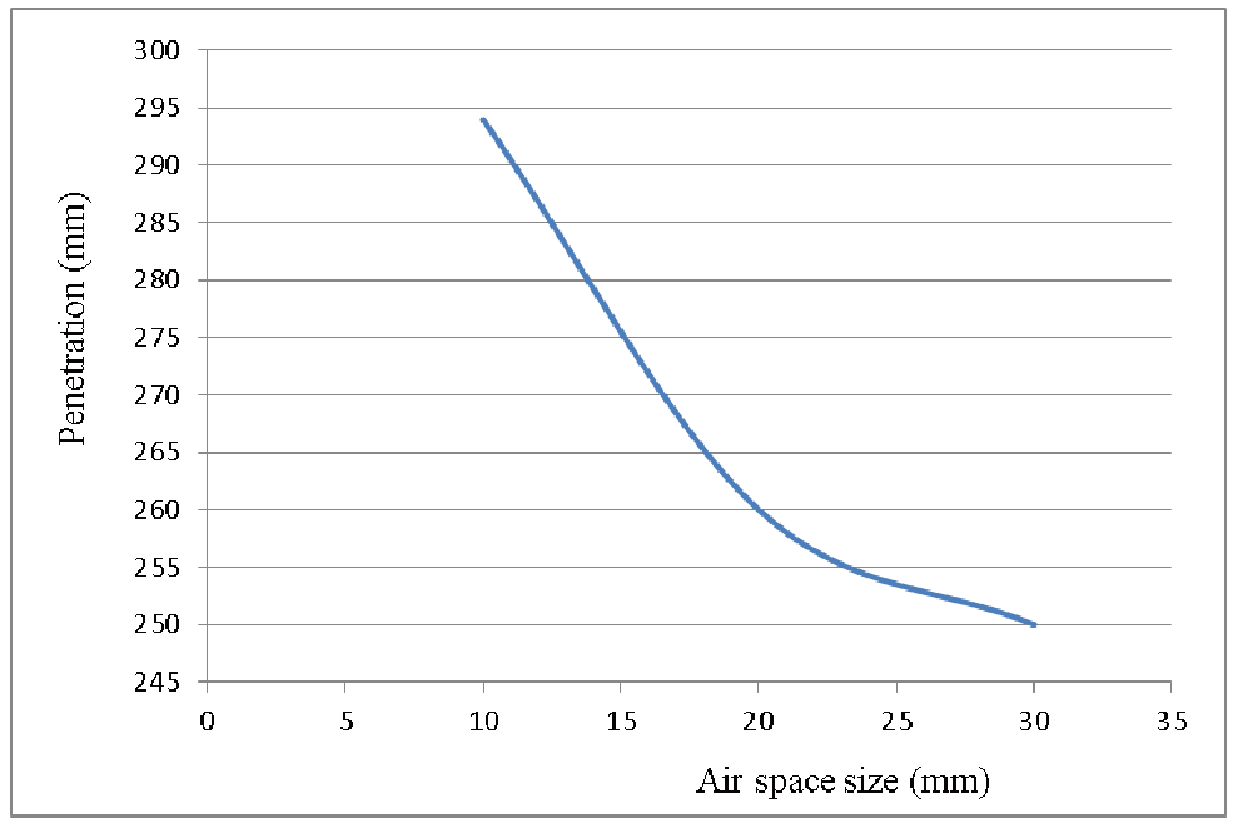

Fig. 17 Penetration depth depending on gap size of air space

Tab. 7 shows the comparison of the time and depth of penetration values in two cases. Obviously, the movement time of the slug does not depend on the gaps size between the target plates. In the case of penetration of plates with gaps, the jet has a greater velocity with larger gaps between plates of target. 
Tab. 7 Comparison of the influence of gap sizes on penetration depths

\begin{tabular}{|l|c|c|}
\hline Air space gap size & $10 \mathrm{~mm}$ & $20 \mathrm{~mm}$ \\
\hline Time to separate the jet from the slug [ms] & $1.933 \times 10^{-2}$ & $1.926 \times 10^{-2}$ \\
\hline The slug moves to the first plate [ms] & $2.747 \times 10^{-1}$ & $2.697 \times 10^{-1}$ \\
\hline Time to stop the jet [ms] & $3.626 \times 10^{-1}$ & $4.053 \times 10^{-1}$ \\
\hline $\begin{array}{l}\text { Velocity of jet at the moment of separation } \\
\text { from the slug [m s }{ }^{-1} \text { ] }\end{array}$ & 6805 & 6810 \\
\hline $\begin{array}{l}\text { Velocity of jet at the moment of the slug on } \\
\text { the first plate [m s }{ }^{-1} \text { ] }\end{array}$ & 2230 & 2316 \\
\hline Penetration depth [mm] & 295 & 260 \\
\hline
\end{tabular}

\subsection{Simulation of Target Materials Properties Effect}

Figs 18-20 compare the jet velocities at the different penetration depths in all three cases of the plate arrangement of the target.

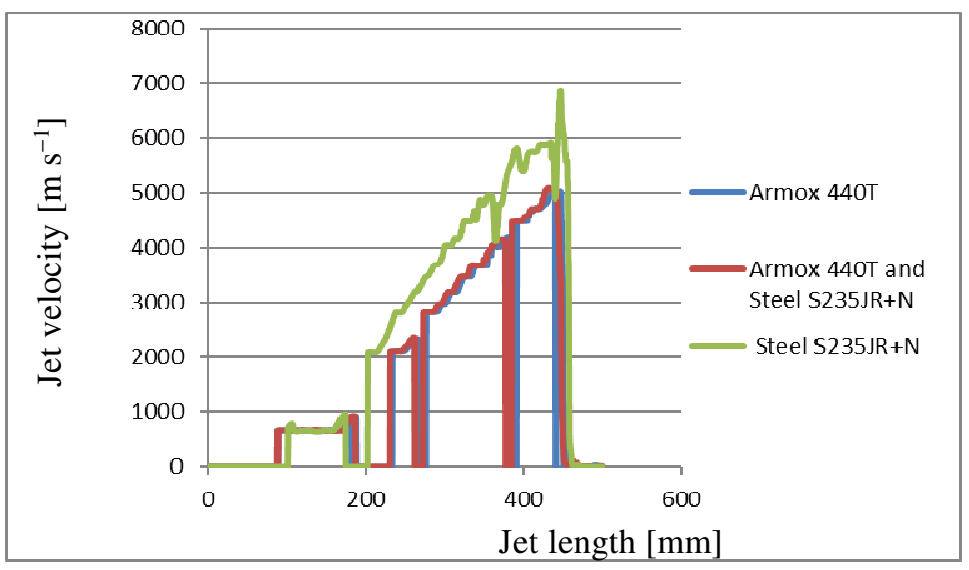

Fig. 18 Jet velocities depending on jet length at $120 \mathrm{~mm}$ penetration depth

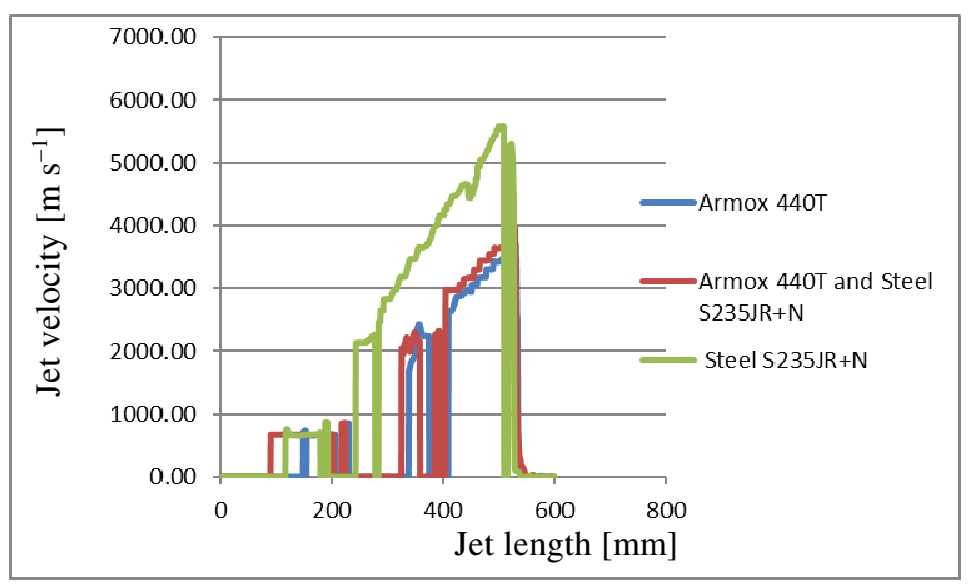

Fig. 19 Jet velocities depending on jet length at $200 \mathrm{~mm}$ penetration depth 


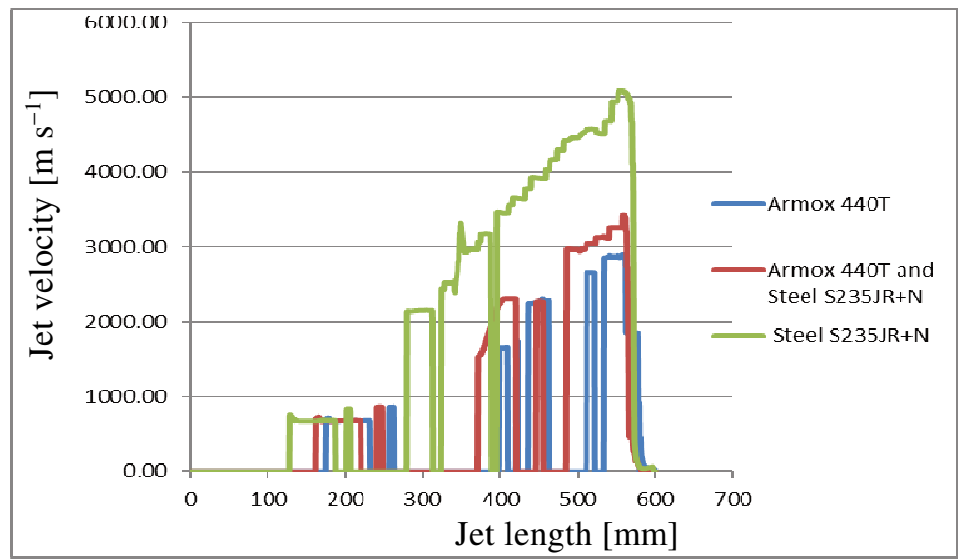

Fig. 20 Jet velocities depending on jet length at $240 \mathrm{~mm}$ penetration depth

At $120 \mathrm{~mm}$ penetration depth in the target formed by Armox 440T plates or the combination of Armox 440T and S235JR plates, the jet velocities and their structure are very similar. The jet tip velocity moving in the target formed by the Armox 440T and S235JR plate combination is $5048 \mathrm{~m} \mathrm{~s}^{-1}$. In case of the target composed only of Armox 440T plates, the jet tip velocity is $5000 \mathrm{~m} \mathrm{~s}^{-1}$ and $6920 \mathrm{~m} \mathrm{~s}^{-1}$ in case of the penetration into the S235JR plates.

The jet penetrating into the target composed of Armox 440T plates is divided into multiple sections (Figs 19 and 20). After the jet penetration at the depth of $200 \mathrm{~mm}$ into the S235JR plates, the jet tip velocity is $5630 \mathrm{~m} \mathrm{~s}^{-1}$. It is about 1.53 times greater than the jet tip velocity penetrating into the target from the Armox 440T plates and 1.41 times greater than the jet tip velocity penetrating into the target formed by Armox 440T and S235JR.

At $240 \mathrm{~mm}$ penetration depth in the S235JR plate target, the jet velocity is $5160 \mathrm{~m} \mathrm{~s}^{-1}$, which is 1.78 times greater than the jet tip velocity penetrating into the target from the Armox 440T plates and 1.49 times greater than the jet tip velocity penetrating into target from Armox 440T and S235JR plates.

Tab. 8 shows the comparison of time and the jet velocity simulation results depending on the penetration depth of three cases plate arrangement of the target.

Tab. 8 Comparison of time and jet tip velocities depending on the penetration depth

\begin{tabular}{|c|c|c|c|c|c|c|}
\hline \multirow{2}{*}{ Target } & \multicolumn{2}{|c|}{ Armox 440T } & \multicolumn{2}{c|}{ Armox 440T + S235JR } & \multicolumn{2}{c|}{ S235JR } \\
\cline { 2 - 7 } Depth & Time $[\mathrm{ms}]$ & $\begin{array}{c}\text { Velocity } \\
{\left[\mathrm{m} \mathrm{s}^{-1}\right]}\end{array}$ & Time $[\mathrm{ms}]$ & $\begin{array}{c}\text { Velocity } \\
{\left[\mathrm{m} \mathrm{s}^{-1}\right]}\end{array}$ & Time $[\mathrm{ms}]$ & $\begin{array}{c}\text { Velocity } \\
{\left[\mathrm{m} \mathrm{s}^{-1}\right]}\end{array}$ \\
\hline $120 \mathrm{~mm}$ & $4.471 \times 10^{-2}$ & 5000 & $4.324 \times 10^{-2}$ & 5048 & $2.97 \times 10^{-2}$ & 6920 \\
\hline $200 \mathrm{~mm}$ & $9.39 \times 10^{-2}$ & 3682 & $8.69 \times 10^{-2}$ & 3989 & $4.912 \times 10^{-2}$ & 5630 \\
\hline $240 \mathrm{~mm}$ & $1.326 \times 10^{-1}$ & 2893 & $1.144 \times 10^{-1}$ & 3452 & $6.634 \times 10^{-2}$ & 5160 \\
\hline
\end{tabular}


Figs 21-23 show the results of the penetration simulation - penetration depth for all three variations of target.

It can be seen from Figs 21-23 that the penetration depth in the target from the S235JR plates is greater than $400 \mathrm{~mm}$. It is about 1.35 times higher than the penetration depth in the target from the Armox 440T plates $(305 \mathrm{~mm})$ and 1.3 times higher than that one in the target composed from the Armox 440T and S235JR plates with a penetration depth value of $320 \mathrm{~mm}$.

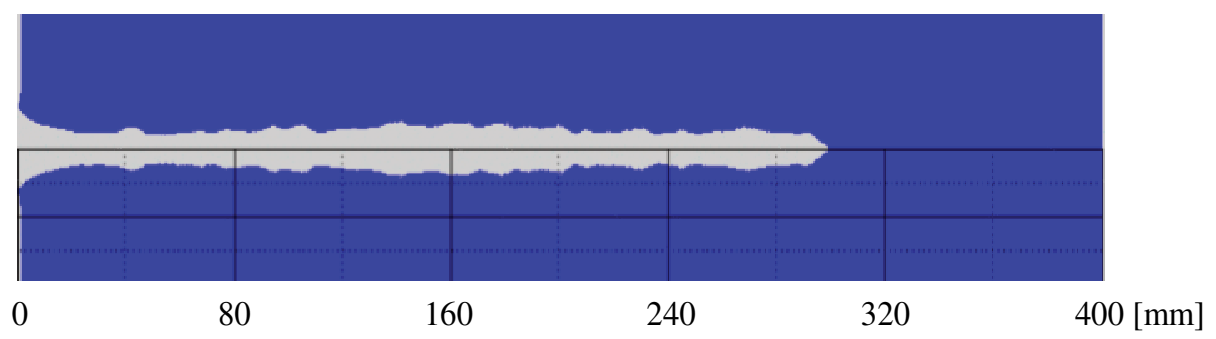

Fig. 21 The target composed of ARMOX $440 T$ plates after penetration

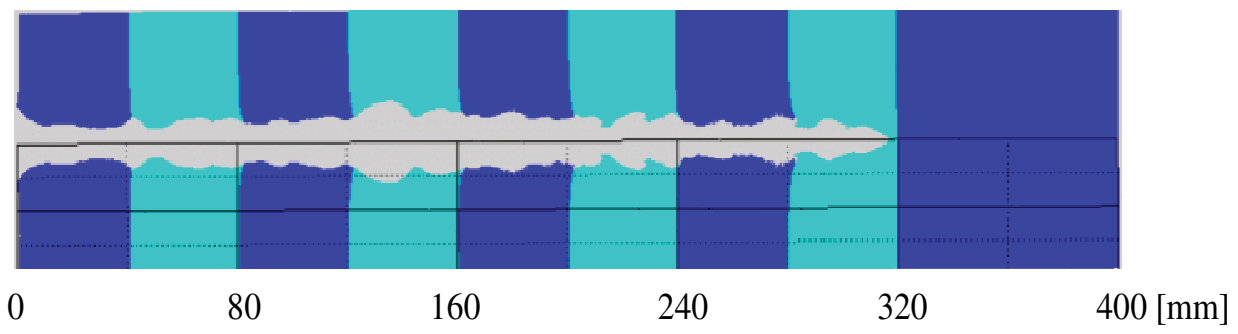

Fig. 22 The target composed of ARMOX $440 T$ and S235JR plates after penetration

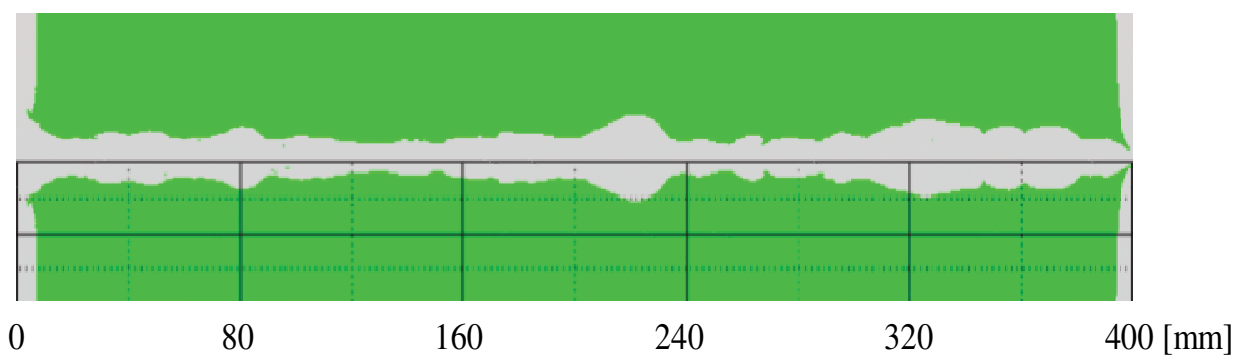

Fig. 23 The target composed of S235JR plates after penetration

\subsection{Comparison of Simulation and Experimental Results}

The results of experiments carried out according to Tab. 6 and results of simulation are introduced in Tab. 9.

Comparing the penetration depth values in Tab. 9, the effect of the target material properties on the penetration depth is obvious. In case of penetration experiment using the S235JR plates, 20 plates were completely penetrated and the $21^{\text {st }}$ plate was partially penetrated. 
Tab. 9 Results of experiments

\begin{tabular}{|c|c|c|c|c|}
\hline \multicolumn{2}{|c|}{ Type of test } & $\begin{array}{l}\text { Penetration } \\
\text { depth }[\mathrm{mm}]\end{array}$ & $\begin{array}{c}\text { Simulation } \\
\text { depth [mm] }\end{array}$ & $\begin{array}{c}\text { Difference } \\
{[\%]}\end{array}$ \\
\hline \multirow{3}{*}{$\begin{array}{l}\text { Armour mate- } \\
\text { rial effect } \\
\text { without gaps }\end{array}$} & Armox 440T & $320,305,301$ & 305 & 1.2 \\
\hline & S235JR & 404,405 & 410 & 1.3 \\
\hline & $\begin{array}{l}\text { Armox 440T + } \\
\text { S235JR }\end{array}$ & 361 & 320 & 12.8 \\
\hline \multirow{2}{*}{$\begin{array}{l}\text { Gaps effect } \\
\text { (Armox 440T) }\end{array}$} & $10 \mathrm{~mm}$ & 280,305 & 295 & 0.3 \\
\hline & $20 \mathrm{~mm}$ & 270,263 & 260 & 2.5 \\
\hline
\end{tabular}

A comparison of the experimental results using the armour Armox 440T without gaps and using two different gaps is shown in Fig. 24. It is obvious that the penetration into the target decreases with larger gaps size of air space.

It is also obvious from Tab. 9 that the differences of the average experimental values and simulation results are not so high, i.e. in the range from $0.3 \%$ to $2.5 \%$. In case of the composed target from two introduced steels, the difference is $12.8 \%$.

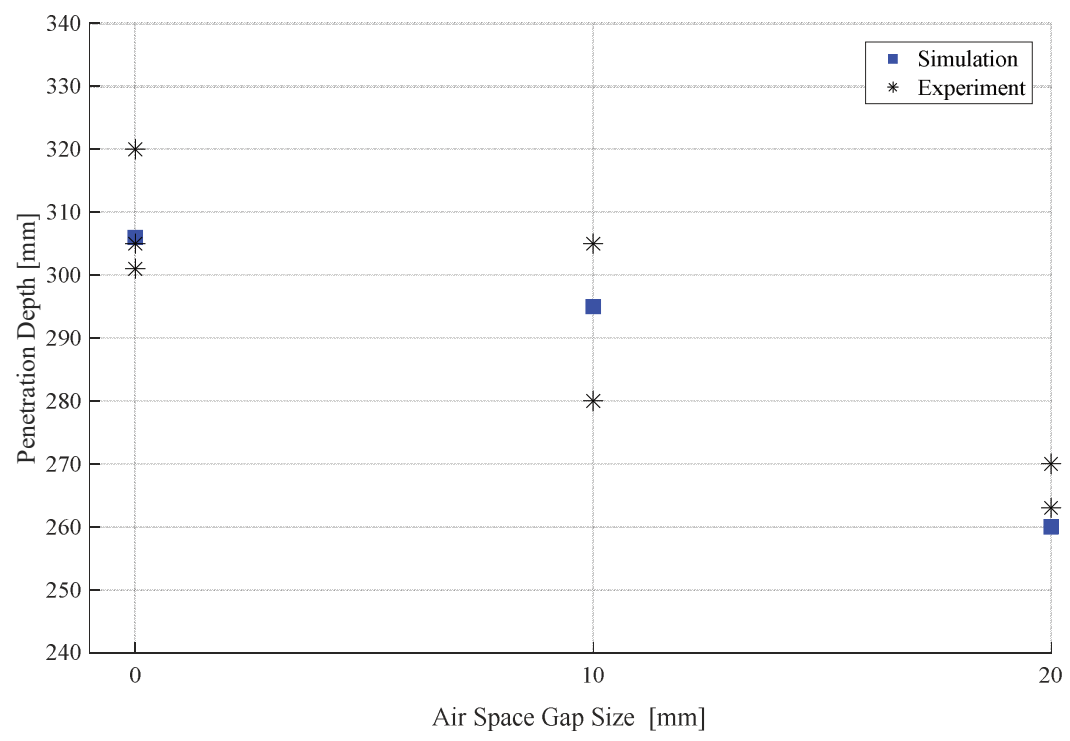

Fig. 24 Comparison of penetration depths at different gaps between plates obtained experimentally and by simulation

\section{Conclusion}

In this article, the 2D simulation model using ANSYS AUTODYN was built to observe/study the effect of the target materials properties as well as the gaps sizes between target plates on the penetration depth values.

Comparison of simulation and experimental results proves their very good correspondence with exception of the armour combination. Therefore, the ANSYS 
AUTODYN use for the penetration simulation of the armours of various properties and structures is possible and expedient when required input armour characteristics are known. Of course, the simulation results verification by the higher number of experiments is necessary. In this case, the higher number of PG-7V warheads or another HEAT ammunition for experiments were not available.

Despite the small amount of experiments, significant conclusions have been proved. The penetration depth of the target composed of the armour plates is comparable with that one of homogenous ballistic protection introduced for this ammunition. The regular gaps between the armour plates decrease the penetration depth. In spite of that, the penetration of armoured vehicles is still sufficient.

\section{References}

[1] SMOLIK, J. Calculation and Construction of Shaped Charge (in Czech). Brno: VAAZ, 1965. 95 p.

[2] WALTERS, W.P and ZUKAS, J.A. Fundamentals of Shaped Charges. New York: Wiley, 1989. 398 p. ISBN 0-471-62172-2.

[3] WANG, C., XU, W. and YUEN, S.C.K. Penetration of Shaped Charge into Layered and Spaced Concrete Targets. International Journal of Impact Engineering, 2018, vol. 112, p. 193-206. DOI 10.1016/j.ijimpeng.2017.10.013.

[4] GUO, H., ZHENG, Y., YU, Q., GE, C.F. and WANG, H. Penetration Behaviour of Reactive Liner Shaped Charge Jet Impacting Thick Steel Plates. International Journal of Impact Engineering, 2019, vol. 126, p. 76-84. DOI 10.1016/ j.ijimpeng.2018.12.005.

[5] WANG, C., XU, W. and LI, T. Experimental and Numerical Studies on Penetration of Shaped Charge into Concrete and Pebble Layered Targets. International Journal of Multiphasic, 2017, vol. 11, no. 3, p. 295-314. DOI 10.21152/17509548.11.3.295.

[6] MURPHY, M.J. Development of a $71 \mathrm{~mm}$ Two-Stage Warhead. (UCID-19651). Livermore (USA): Lawrence Livermore National Laboratory, 1982.

[7] SIMON, J., DIPERSIO, R. and MERENDINO, A.B. The Penetration Capability and Effectiveness of a Precision Shaped Charge Warhead. (Memorandum Report No. 1636). Aberdeen: Ballistic Research Laboratory, 1965. AD \#5249451.

[8] DIPERSIO, R. and SIMON, J. Theory of Residual Penetration by Ideal Shaped Charge Jets. (Report No. 1313). Aberdeen: Ballistic Research Laboratory, 1966.

[9] MERENDINO, A.B. and VITALI, R. The Penetration of Shaped Charge Jets into Steel and Aluminium Targets of Various Strengths. (Memorandum Report No. 1932). Aberdeen: Ballistic Research Laboratory, 1968.

[10] HELD, M. Characterizing Shaped Charge Performance by Stand-off Behaviour. In Proceedings of the $7^{\text {th }}$ International Symposium on Ballistics. Haag: MBB $\mathrm{GmbH}, 1983.10 \mathrm{p}$.

[11] DEHN, J.T. A Unified Theory of Penetration. (Technical Report BRL-TR-2770). Aberdeen: Ballistic Research Laboratory, 1986.

[12] FOSTER, J.S. Integrated Flash Radiograph Analysis - an Approach to Studying Time-Dependent Phenomena in the Explosive Formation and Projection of Met- 
als. In Proceedings of $7^{\text {th }}$ Annual Technical Meeting on Physical Explosion. Livermore: Lawrence Livermore National Laboratory, 1981.

[13] ANSYS Autodyne User's Manual. Canonsburg: Ansys Inc., 2017, 512 p.

[14] Armox ${ }^{\circledR} 440 T$ [online]. [viewed 2020-02-11]. Available from: www.ssab.com/ products/brands/armox/armox-440t

[15] Plates Product Catalogue 2019 [online]. [viewed 2020-02-11]. Available from: www.vitkovicesteel.com/data/soubory/plechy/Katalog_plechy_A4_2018_cely_op rava1-40_2_tisk6_web.pdf 